\title{
В.Н. Конышев
}

Неореализм сформировался на исходе 1970-х годов как обновленная версия реализма*, долгое время занимавшего ключевое место в теории международных отношений. На рецептах неореалистов выросло не одно поколение американских политиков. Изучение этой парадигмы позволяет уяснить специфику современных споров в академической среде, составить более полное представление о тенденциях развития политической мысли, понять стереотипы мышления политической элиты США, раскрыть подоплеку подготовки решений по военно-политическим вопросам, отделив ее от того образа, который предлагается для внешнего потребления**.

В отличие от "классического" реализма, неореализм ориентирован не просто на исследование отношений между государствами, но на построение системной теории международной политики. Он обращает внимание на роль негосударственных политических акторов, изучает условия международного сотрудничества. Если для реалистов старого образца наращивание силы - абсолютное благо для государства, то неореалисты делают упор на безопасность и говорят о той мере силы, которая способна ее обеспечить. Предпринимаются попытки детального анализа природы насилия и более четкого различения понятий “власть”, “сила”, “мощь”, “влияние”, “авторитет”. Следует отметить также подчеркнуто дедуктивный характер неореализма в противовес интуитивизму и индуктивности реализма “классического".

Появление неореализма принято связывать выходом в свет книги К.Уолтса "Теория международной политики" [Waltz 1979]. Впервые данный термин

146 был использован Р.Эшли [Ashly 1981], обратившего внимание на новаторские идеи этого автора. Сам Уолтс первоначально определял свой подход как “структурный реализм" и лишь со временем согласился с названием "неореализм”. В дальнейшем к неореалистическим стали относить и некоторые другие концепции обновления, в т.ч. теорию циклов [Modelski 1987] и гегемонистской стабильности [Gilpin 1981], а также такие междисциплинарные направления, как историко-системный [Kennedy 1987] и нелинейный анализ международной политики [Czervinski 1998]. Тем не менее под неореализмом в узком смысле обычно понимают именно концепцию Уолтса и его последователей***. Рассмотрению полемики вокруг этой концепции, до сих пор вызывающей острые споры в научных кругах [см., напр. Ruggi 1983, 1989; Buzan et al. 1993; Wohlforth 1995; Deudney 1995, 1997; Jervis 1997; Legro, Moravchik 1999], и посвящена настоящая статья.

Методологическим основанием предложенной Уолтсом системной теории политики стал не популярный в США структурно-функциональный анализ, а французский структурализм, рассматривающий структуры в качестве объек-

КОНЫШЕВ Валерий Николаевич - кандидат исторических наук, старший преподаватель факультета международных отношений СПбГУ.

* К числу наиболее известных представителей данного направления, помимо Г.Моргентау [см., напр. Morgenthau 1948], относятся Е.Kapp [Carr 1946], Э.Вулферс [Wolfers1962], Г.Киссенджер [Kissinger 1957] и С.Хоффман [Hoffman 1965].

** На идеи неореалистов склонна опираться, в частности, администрация Буша-младшего [Doyle 1997: 38; Сергунин 2001: 12-15].

*** Среди близких к уолтсовским по научному мировоззрению работ см., напр. Krasner 1978,1985; Posen 1984;. Walt 1987; Mandelbaum 1988; Ikenberry et al. 1988; Lake 1988; Betts 1994; Snyder 1997; Mearsheimer 2001. 
тивных факторов, которые влияют на деятельность общества посредством формирования мотиваций (как правило, неосознанных). С помощью данной концепции исследователь надеялся преодолеть индуктивизм и эмпиризм* в политической науке, ведущие в тупик из-за сложности и многомерности объекта исследования. "Опираться на принцип объединения [индукции] без хотя бы некоторого проблеска теории - все равно, что стрелять из ружья в направлении ненаблюдаемой цели", - отмечал он [Waltz 1975: 15]. "Если мы пойдем по пути индуктивизма, то будем иметь дело лишь с фрагментами проблемы. Представление в том, что фрагменты... могут считаться независимыми переменными, чей суммарный эффект будет объяснять... движение зависимой переменной, строится лишь на вере" [Waltz 1979: 4]. Бихевиористы, критиковавшие "классический" реализм за ненаучность и пытавшиеся решить эту проблему через привлечение методов других наук [см., напр. Russett 1972], в действительности ушли ненамного дальше реалистов эпохи Моргентау. По Уолтсу, теория должна не просто давать совокупность правдоподобных гипотез, но и обеспечивать их универсальное объяснение.

Стремление Уолтса к более строгой трактовке понятия теории, чем это принято в гуманитарных науках, где всегда преобладали описательные теории с довольно ограниченной доказательной силой, в значительной мере объясняется влиянием на мировоззрение ученого современной критической философии. Продолжая традицию Канта, представители этого направления выдвинули три критерия научной состоятельности общественной теории [см. Popper 1959, 1965; Aggassi 1975; Fayerabend 1981; Watkins 1984; Miller 1994]. По их мнению, истинность гипотезы определяется не широтой эмпирической базы, на которой она построена, а прежде всего ее способностью выдержать проверку опытом. Поскольку всякое знание относительно и неполно, любая гипотеза оправданна лишь до тех пор, пока она подтверждается практикой. Другой критерий - “дедуктивная систематизированность” теоретических предположений, предполагающая, что из каждого положения теории выводится максимум следствий. Тем самым теория становится более строгой, согласованной и способной развиваться по пути самокритики. Наконец, в основании теории должен лежать так наз. “методологический индивидуализм”, т.е. “общественное целое" должно объясняться через взаимодействие его элементарных субъектов. Именно такое взаимодействие и порождает структурные отношения и институты в виде рынка, государства, международной системы и т.д.

Согласно критико-философскому взгляду, сложное целое нельзя постичь непосредственно, его требуется воссоздать с помощью воображения. Отсюда необходимость дедуктивной логики для общественных наук, где целое есть теоретический конструкт, который надо аналитически разложить на части, а затем “дедуктивно вывести". Если целое нельзя реконструировать, отталкиваясь от поведения элементарных сущностей, оно непознаваемо [Tellis 1996: 5-9, 79-83, 88]. И хотя структурная теория Уолтса не полностью удовлетворяет этим критериям, даже критики признают, что она ближе других подошла к их реализации.

Социальные структуры не обнаруживаются непосредственно в опыте, а рационально выводятся из него. Однако они - не фантазия или игра ума: структуры существуют в “глубине" социальной действительности. Выделение структур не требует обращения к каким-то внешним доводам. В этом смысле данная категория самодостаточна, и структуралисты не рассматривают влияние на нее внешних факторов.

Понятие “структура" имеет несколько значений. Согласно одному из них, структуры есть некие “компенсирующие устройства”, которые, несмотря на вариации исходных условий, обеспечивают выравнивание, регулярность результата и создаются обшеством для решения конкретных задач (партии, парламенты, правительства). Подобные образования Уолтс называет “агентами"

* Они выражаются в постоянном расширении массива изучаемых фактов и построении на этой основе все новых обобщений, зависимостей и гипотез. 
(agent, agency), имея в виду, что они являются субъектами действия. Структуры, которыми занимается структурная теория, совсем иного рода - это "набор ограничивающих условий” [Waltz 1979: 73]. Среди них свободный экономический рынок и международно-политические "механизмы отбора", не поддающиеся, в отличие от "агентов”, непосредственному наблюдению. "Международная структура возникает из взаимодействия государств; она одновременно удерживает их от определенных действий и стимулирует к другим”, - подчеркивает Уолтс [Waltz 1991: 29]. "Чтобы определить структуру, нужно отвлечься от того, как действуют единицы [государства], и сконцентрироваться на их отношении* друг к другу (на том, как они организованы или упорядочены). Действие... осуществляется на уровне единиц. [Но] отношения... не принадлежат единицам. Упорядоченность (arrangement) единиц принадлежит всей системе" [Waltz 1979: 80]. Структура менее подвержена изменениям, чем поведение личности или политика отдельных государств. Эта категория дает понимание того, чем государства отличаются друг от друга, как они соотносятся между собой с точки зрения способности к действию.

Для структуры международной политики характерны децентрализация и отсутствие высшего руководящего органа, т.е. анархичность. Но последнее понятие не является в данном случае антонимом упорядоченности. Раскрывая эту мысль, Уолтс прибегает к аналогии со свободной рыночной конкуренцией, когда упорядоченность спонтанно формируется из взаимодействий независимых фирм и предпринимателей. Точно так же международная структура складывается из разнонаправленной политики реальных государств и лишена какой-либо изначально данной “внутренней идеи” развития.

Важнейшей характеристикой структуры международной политики Уолтс считает распределение силы между государствами. Речь идет не о силе отдельных государств, а именно о распределении, так как оно относится к свойствам структуры, указывая на отношение, способ упорядочивания (группировки) единиц. Если анархия остается неизменным атрибутом международной системы, то распределение силы меняется. Поэтому лишь с его помощью можно понять, как государства действуют на международной арене и почему происходят изменения международной системы в целом. Из этого следует, что распределение силы в наибольшей степени обеспечивает объяснительные возможности теории международной политики [Waltz 1979: 82, 88-99].

Наличие структуры накладывает определенные ограничения на субъекты политики, что позволяет говорить о воздействии структуры, или структурной силе. Будучи отношением и регулятором поведения, она выступает как механизм, который связывает индивидуальные действия государств и процессы международной политики. При этом конечный итог нередко противоречит намерениям акторов. Так, соотношение сил, сложившееся в результате наращивания силы каждым государством, может оказаться прямо противоположным ожиданиям основных участников. Важно отметить, что, в отличие от “агентов”, структура оказывает свое влияние косвенно, через социализацию и соревнование между субъектами политики.

Очевидно, что подобным образом понятая структура довольно статична. Исходя из этого, критики Уолтса делают вывод о непригодности данной категории для анализа динамических процессов. Но структуры все же имеют свою динамику в том смысле, что постоянно воздействуют на поведение государств. Именно они позволяют выявлять и изучать постоянство и повторяемость в политике. "Политическая структура создает сходство в процессе их [государств] функционирования в течение всего времени, пока структура продолжает существовать" [Waltz 1979: 70], - отмечает Уолтс и подчеркивает, что с точки зрения теоретического анализа такое сходство гораздо важнее изменений, индивидуальных и неповторимых.

\footnotetext{
* Уолтс разводит понятия “отношение” (relation) и “действие” (action). Отношение как упорядо-
} чивание относится к структуре, а действие - к ее элементам. 
Несмотря на присуший ей консерватизм, структура международной политики все же претерпевает определенные изменения. Уолтс выделяет два типа таких изменений. K первому относятся собственно структурные трансформации, которые касаются принципа упорядочивания системы. В этом плане современная международная структура довольно устойчива и сохраняется в неизменном виде пять столетий. Ко второму - внутрисистемные сдвиги, которые идут непрерывно, но не затрагивают существа структуры. Обычно они проявляются на уровне взаимодействий единиц: развитие средств связи и коммуникаций; создание новых видов оружия и военных технологий; исчезновение старых и появление новых альянсов; смены политического строя и внешнеполитических интересов государств. Эти изменения могут приобретать планетарные масштабы и иметь глобальное значение, оказывая влияние на другие процессы, происходящие в международной системе. (Так, возникновение транснациональных корпораций способствует размыванию национальных границ.) Реже происходят изменения, меняющие конфигурацию международной структуры, такие как смена полярности [Waltz 1979: 67, 69-71]. ции Уолтса. Он заключается в том, что теория не объясняет причин возникновения современной международной структуры, а потому - и условий ее возможной трансформации. И действительно, ученый намеренно оставляет за скобками проблему накопления изменений. Данная особенность его теории вытекает из принципов структурализма, который делает акцент на синхронных аспектах предмета исследования. История - это особый способ развития системы, который может обсуждаться лишь после анализа имеющихся структурных отношений [Lane 1970: 11-17; Piaget 1970: 3-16]. Структурализм изучает международную систему не в развитии, а в относительной устойчивости ее существенных свойств. Отвлечение от изменений связано с природой структурного воздействия, которое выступает в качестве спонтанно формирующегося условия отбора, не зависящего от намерений конкретных субъектов политики. Вопрос, когда и почему в системе происходят радикальные сдвиги, например смена полярности, выходит за пределы структурной теории и нуждается в привлечении внешних гипотез (экономический упадок великой державы и т.п.).

Недостатки подобного подхода очевидны, однако он имеет и свои преимущества, позволяя вывести за рамки исследования фактор исторической случайности. В противном случае теория сразу бы утратила строгость и доказательность, которую Уолтс пытается достичь по примеру естественных наук, и вернулась бы к интуитивизму классического реализма. Разумеется, с точки зрения традиционной исторической науки вопрос о наличии в политике общих законов остается спорным. Но, как бы то ни было, понятие относительно устойчивой структуры дает возможность построить общую теорию политики, несмотря на ее неизбежную ограниченность.

О продуктивности такого подхода свидетельствуют работы Уолтса, посвященные реальным политическим вопросам. Рассуждения ученого о развитии современной международной системы в направлении многополярности, о формировании нового центра силы в АТР, о преувеличении масштабов и глубины глобализации [cм. Waltz 2000a,b] вполне убедительны. Примечательно, что они соответствуют основным положениям теории, сформулированной более 20 лет назад. Иными словами, несмотря на антиисторизм, концепция Уолтса не утратила своего значения и после драматических событий конца XX в., что указывает на наличие у нее высокого эвристического потенциала.

Здесь следует чуть подробнее остановиться на методологии Уолтса. Как уже говорилось, Уолтс трактует теорию в духе скорее естественных, нежели гуманитарных наук: “Теории объясняют законы... Это значение не соответствует принятому в традиционной политической науке, которая больше ориентирована на философскую интерпретацию, чем на теоретическое объяснение" 
[Waltz 1979: 6]. Рассматривая соотношение между теорией и действительностью, Уолтс обращает внимание на то, что реальность существует независимо от описывающих ее теорий и не совпадает с ними: "Истина в теории может не быть таковой в практике” [Waltz 1979: 7]. Соответственно, теории дают лишь неполное знание о мире: "Теории - не описания реального мира; они лишь инструменты, которые мы создаем, чтобы понять некоторую его часть" [Waltz 1975: 8]. Поэтому тот факт, что структурный реализм не в состоянии объяснить, скажем, причины окончания холодной войны, не свидетельствует о его несостоятельности как теории.

Возражения критиков вызывает также тезис Уолтса об анархичности структуры международной политики. По их мнению, противопоставление иерархии и анархии как принципов организации международной системы упрощает реальное положение вещей, ибо ни то, ни другое невозможно в чистом виде. Образуя анархическую структуру, государства тем не менее могут иметь близкие политические традиции, нормы, ценности, да и само их существование опирается на признание другими государствами. В доказательство приводится множество эмпирических фактов.

На наш взгляд, подобная критика полностью необоснованна. И дело даже не в том, что у Уолтса упорядоченность не противоречит анархичности, а в том, что его теория носит преимущественно дедуктивный характер. В этом случае некорректно использовать факты в качестве доказательного критерия, ибо вследствие неповторимости истории они уводят в область недоказуемого. Чтобы обеспечить дедуктивный объяснительный механизм, необходимо выработать по возможности простой набор неоспоримых понятий. Такая позиция вполне защищает Уолтса от упреков в упрощении, которые он вводит сознательно. Более того, упрощение действительной картины мира предполагает любая теория, если она нацелена на объяснение, а не на простое описание существующего.

Уолтс весьма критически оценивает прежние попытки комплексного исследования международной политики, считая их неспособными выявить собственно системные влияния. При этом он имеет в виду прежде всего структурнофункциональный анализ, который предполагает изучение целого через свойства и взаимодействия отдельных элементов, фокусируя внимание на роли государств, политических элит, бюрократий и других субъектов политики. Как справедливо отмечает Уолтс, на этом пути есть несколько принципиальных сложностей: число элементов международной системы слишком велико, чтобы составить цельную картину из попарных взаимодействий; системные свойства нельзя вывести из свойств и взаимодействий акторов; не все системные понятия приложимы к ее элементам (например, полярность международной системы) [Waltz 1979: 60-61, 64-65]*. Поэтому, в отличие от структурализма, структурно-функциональный подход способен дать только частную теорию, которая может работать лишь в совершенно определенных исторических условиях.

Внедрение в политические науки математических методов, особенно усилившееся в последние годы в связи с совершенствованием компьютерных технологий, породило новую волну интереса к различного рода структурнофункциональным моделям. Характерным примером является все более частое обращение к общей теории систем при изучении международной политики [cм., напр. Jervis 1997]. Но подобный подход, по сути своей экстенсивный, не в состоянии преодолеть упомянутые трудности. По верному замечанию Уолтca, методы других наук, в т.ч. естественных, продуктивны в той мере, в какой помогают выделить системное (в терминологии Уолтса - структурное) влияние. Они не должны подменять собой научно-теоретический анализ. Другими словами, исследователь не должен использовать их в качестве “панацеи".

Системный анализ в понимании Уолтса заключается в том, чтобы “во-первых, проследить ожидаемое развитие международных систем, в частности вероятное время их жизни и способность к миру, и, во-вторых, выявить, как

* Интерпретацию понятия системности см. также Jervis 1997: 3-28. 
структура системы влияет на взаимодействие единиц, а они, в свою очередь, влияют на структуру” [Waltz 1979: 40]. Объяснительная и прогностическая сила теории проявляется в ее способности "показать, почему круг ожидаемых событий попадает под определенные ограничения; почему случаются повторения в поведении [субъектов]; почему воспроизводятся события, в т.ч. и те, которые не нравятся некоторым акторам" [Waltz 1979: 69]. Прогнозы системной теории носят общий характер: ее интересуют причины не конкретной войны, а войны как общего явления. Критики зачастую не замечают этой особенности структурного реализма, видя в невозможности предсказать политику того или иного государства существенный недостаток теории. Но ее внутренняя логика и не предполагает такого рода ответов.

К сожалению, в неореализме Уолтса недостаточно разработан вопрос об обратном влиянии государства на международную структуру. Многие считают, что в результате влияние структуры на государство преувеличено. Некоторые критики даже утверждают, будто из теории Уолтса следует, что государство, чья политика противоречит структурным тенденциям, неизбежно проигрывает, и наоборот. Речь идет, в частности, о политике баланса сил. Однако, на наш взгляд, подобный вывод также обусловлен неточным истолкованием теории.

Уолтсовскую концепцию баланса сил нужно рассматривать сквозь призму структурного воздействия. Не отрицая основных положений Realpolitik*, структуралистский подход показывает, что, несмотря на различия между государствами и их лидерами, а также независимо от их намерений, методы управления политикой в анархичной структуре неизбежно повторяются. Подобно микроэкономическим законам, баланс сил как состояние системы формируется объективно, поскольку анархичная структура международной политики, возникающая из независимой деятельности суверенных государств, стремящихся выжить, создает условия для его спонтанного воспроизводства.

Для Уолтса политика баланса сил, которая выражается в наращивании моши или создании альянсов, отнюдь не является единственно возможной, как это иногда пытаются представить его оппоненты. Перед государством открыты и другие стратегии - например, оно может присоединиться к более сильному государству или, напротив, добиваться лидирующего положения. В то же время политика баланса сил имеет преобладающее значение, поскольку именно к ней побуждает анархичная международная структура, которая в противном случае давно бы стала иерархической. Концепция баланса сил служит основой для общих рассуждений об интересах и мотивах государств, об их ожидаемых действиях с учетом системных ограничений. Но из нее нельзя вывести политику конкретного государства, так как она зависит не только от системного влияния, но и от внутриполитических факторов [Waltz 1979: 116-127]. Отсюда следует, что теория баланса сил вполне применима к современной международной системе c ее тенденцией к глобализации и эрозии государственного суверенитета. Она по-прежнему отражает общее условие существования государств в системе, которая остается анархичной, несмотря на смену полярности.

Согласно структурной теории, главным субъектом международной политики выступает государство, а его основная функция заключается в защите суверенитета. Оба этих постулата наталкиваются на серьезную критику. Первое утверждение начало оспариваться еще в 1960 - 1970-е годы, когда исследователи обратили внимание на рост взаимозависимости субъектов международной политики и активизацию негосударственных акторов [см., напр. Keohane, Nye 1977]. О падении роли государства вновь заговорили в 1990-е годы в кон-

* Напомним, что, согласно данной концепции, государство нацелено на защиту своих национальных интересов; международная политика формируется в условиях нерегулируемого соревнования государств; стратегия, которая учитывает такой характер политики, в наибольшей мере отвечает государственным интересам; успех политики состоит в наращивании силы государства. 
тексте дискуссий о новой парадигме развития - переходе от взаимозависимости некоторых сегментов мировой экономики и политики к глобализации*. Не меньшие сомнения порождает положение о суверенитете как важнейшем атрибуте государства. Ссылаясь на опыт средних веков, когда понятие суверенитета еще не сформировалось, а также на тенденцию к его исчезновению в эпоху постмодерна, противники данной концепции доказывают, что суверенитет - преходящий, а не сущностный признак международной системы. Вызывает возражения и тезис неореализма об относительной независимости государства как субъекта международной политики от внутриполитических факторов, таких как характер политических институтов или позиция отдельных сегментов обшества. В частности, высказывается мнение, что окончание холодной войны, наиболее заметное событие конца XX в., не имеет структурных объяснений, ибо коллапс Советского Союза обусловлен провалом реформ Горбачева, т.е. внутриполитическими факторами.

Представляется, что и данное направление критики структурного реализма не вполне обоснованно. Теория Уолтса движется от общего к частному, объясняя не политику конкретного государства, а те характеристики, которые присуши многим. Отсюда вывод: закономерности поведения государства на международной арене зависят главным образом от изменений на уровне международной структуры. Структурные свойства имеют долгосрочный, универсальный и в какой-то мере предсказуемый характер. Системный анализ предполагает абстрагирование от параметров, определяющих идеологию, внутреннюю политику и политическое устройство государства. Защита суверенитета остается главной функцией последнего, потому что без суверенитета невозможно выполнение каких-либо иных функций. Конечно, это положение является сознательным упрощением, и на практике мотивация государства гораздо сложнее, но оно полностью оправданно, если согласиться с выделением политики в автономную сферу деятельности.

Понятие суверенитета порой противопоставляют зависимости в проведении международной политики. Но для Уолтса суверенитет отнюдь не тождествен полной свободе действий, т.е. не исключает “зависимости”. Он лишь означает, что государство "определят само, как оно будет решать внутренние и внешние проблемы, включая и то, станет ли оно искать помощи у других и через принятие обязательств ограничивать собственную свободу. Государства самостоятельно формулируют свою стратегию, свой курс и все остальное, на что направлена их деятельность" [Waltz 1979: 96]. Суверенный выбор может быть сделан в пользу следования в фарватере более сильного государства, как это происходит в странах Восточной Европы после распада СССР.

Аналогичным образом повышение активности негосударственных акторов не мешает государству оставаться основной единицей международной системы. Великие державы по-прежнему оказывают решающее влияние на международную политику. Государства определяют условия деятельности суб- и супранациональных акторов и меняют "правила игры” по мере необходимости [Waltz 1979: 93-95]. Чем выше взаимозависимость, тем важнее роль государства в мировой политике.

Еще один спорный момент касается недооценки Уолтсом набирающей темпы глобализации, которая объективно понижает значимость государства как субъекта политики. Критики утверждают, что структурный реализм не в состоянии учесть целый ряд важнейших факторов (развитие технологий; степень взаимозависимости государств и международного сотрудничества; национализм, который может как соединять, так и разъединять народы, и т.д.), поскольку не ясно, куда их относить, к уровню элементов или системы в целом. Между тем

\footnotetext{
* Взаимозависимость и глобализация различаются не просто объемом и скоростью движения капитала, но и качественно. Если взаимозависимость означает сближение экономических и политических интересов государств, то глобализация подразумевает интеграцию мирового сообщества по типу единого государства.
} 
эти факторы влияют не только на политику отдельных государств, но и на условия их взаимодействия, а также на распределение и перераспределение силы.

По мнению Уолтса, масштабы и глубина глобальных процессов во многом преувеличены. Большая часть мира вообще ими не затронута, в т.ч. Россия, почти вся Африка, Латинская Америка, значительная часть Азии. Доля ВНП, произведенного на экспорт в наиболее экономически развитых странах, равно как степень интеграции мировых финансовых рынков, мало изменилась по сравнению с началом XX в. В США внутри страны потребляются до 90\% товаров и услуг, в Японии и странах Евросоюза доля экспорта не превышает 12\% ВНП [Waltz 2000a: 47-50]. Исследования деятельности современных транснациональных корпораций подтверждают заключение Уолтса: несмотря на все разговоры о глобализации, большинство корпораций и финансово-промышленных групп ориентированы преимущественно на рынки своих государств [Kapstein 1991/1992: 55-62; Hirst, Thompson 1996: 5].

Уолтс подвергает сомнению и довольно широко распространенное представление, будто Соединенные Штаты надолго закрепили за собой роль локомотива глобализации [см., напр. Wohlforth 1999]. С его точки зрения, это физически невозможно, ибо в США проживают лишь 5\% населения планеты и, кроме того, другие страны не будут бесконечно мириться с таким положением и попытаются сбалансировать отношения. Поэтому, считает он, сложившееся к началу нового тысячелетия лидерство США недолговечно и "неестественно” [Waltz 2000a: 56].

Критики не всегда учитывают и еще одну важную особенность структурной теории. Они часто смешивают понятия "взаимодействие” и “отношение". Для Уолтса структура - это отношение, взятое в отвлечении от взаимодействий конкретных государств и других процессов, включая глобальные. Поэтому тезис о том, что размывание суверенитета в современной международной системе делает структурный подход бесполезным, представляется недостаточно обоснованным. То же самое можно сказать и об утверждении, будто понятие структуры неадекватно действительности, поскольку оно не способно охватить собой глобальные процессы. Процессы не относятся к отношениям, поэтому их включение в структуру противоречило бы методологии Уолтса. Можно согласиться, что глобальные процессы заметно влияют на перераспределение силы, а относительная значимость суверенитета падает. Но ни то, ни другое пока не меняет сущностных свойств международной системы, которые довольно устойчиво воспроизводятся. Если же принципы организации международной системы изменятся, то, согласно Уолтсу, для ее описания потребуется другая теория.

Ключевое место в теории Уолтса занимает идея многоуровневого анализа политики, что подразумевает исследование связей на трех уровнях: человек, государство и международная система в целом [Waltz 1959: 238; 2000a: 68]. Подобный подход позволяет учитывать многоплановость политики, отделять частные причины от общих и причины от следствий. Вместе с тем Уолтс указывает на необходимость различения системного анализа на уровне государства и теории внешней политики. Системный взгляд на политику предполагает упор на влияние структуры как ограничивающего и направляющего начала при отвлечении от особенностей конкретных государств и ориентирует на поиск общих закономерностей. Поэтому "реалистическая теория гораздо лучше отвечает на вопрос, что случится, чем - когда это случится. Она не может сказать, когда наступит 'завтра', поскольку имеет дело с воздействиями структуры на государство, а не с тем, как конкретное государство отвечает на эти воздействия" [Waltz 2000b: 27; Waltz 1989: 42]. Прямой причинной связи между отношениями на уровне государств и реакцией на уровне международной политики нет. Она возникает из взаимовлияния между причинами системного и элементного уровней. 
В свою очередь, теория внешней политики направлена на познание специфического: “теории на уровне элементов говорят о том, почему разные элементы ведут себя по-разному, несмотря на их одинаковое положение в системе. Теория внешней политики относится к теориям национального уровня. Она позволяет прогнозировать, каким будет ответ различных государств на внешнее давление" [Waltz 1989: 43]. Полное знание о международной политике дает лишь сочетание структурной теории и теории внешней политики государства. "Структура не объясняет всего, - подчеркивает Уолтс, предостерегая от структурного детерминизма. - ...Чтобы объяснить международную политику, нужно учитывать силу, поведение, взаимодействия государств наряду со структурой, которую они образуют" [Waltz 2000b: 27].

Идея многоуровневого анализа выглядит вполне логично. Однако сам Уолтс сделал лишь первый шаг в направлении ее реализации - от системы к государству, приняв последнее как данность. Как уже отмечалось, проблема обратного влияния государств на систему, не говоря уже о личностном уровне международной политики, осталась в его концепции неразработанной. Если встать на путь последовательного развития принципов структурного реализма, то будущие поколения теоретиков должны аналитически разложить основные элементы структуры (государства) на более мелкие составляющие (индивидов) и затем с помощью дедуктивной логики реконструировать феномен возникновения государства из убеждений, ценностей, стремлений и действий отдельных личностей [Tellis 1996: 91].

К слабым сторонам структурного реализма (как и многих других теорий международных отношений) относится и положение о рациональной природе международной политики. На практике поведение государственных лидеров не всегда до такой степени рационально, как это подразумевает теория. Более того, действия некоторых политических лидеров или маргинальных групп (например, террористов) могут быть иррациональными, противоречащими самим основам жизни. Теория, делающая столь сильный акцент на рациональности субъектов политики, рискует оказаться бесполезной именно тогда, когда политики-практики особенно нуждаются в экспертном мнении.

$$
* \quad * \quad *
$$

В заключение следует отметить, что, несмотря на все критические замечания, теория Уолтса продолжает пользоваться популярностью в научных кругах, и не только США. Тенденции современного мира, связанные с трансформацией международной структуры, размыванием суверенитета и снижением роли государств, глобализацией экономической и других сфер международных отношений, не лишили ее эвристического потенциала. На наш взгляд, этот факт может служить косвенным подтверждением правоты Уолтса, который считает, что такого рода тенденции не означают принципиального изменения международной структуры.

Сергунин А.А. 2001. На пороге XXI века: восприятие проблем международной безопасности Россией и США. - Актуальные проблемы американистики. Нижний Новгород.

Aggassi J. 1975. Science in Flux. Dordrecht.

Ashly R. 1981. Political Realism and Human Interests. - International Studies Quarterly, vol.25, № 2 .

Betts R. K. (ed.) 1994. Conflict after the Cold War. Boston.

Buzan B., Jones Ch., Little R. 1993. The Logic of Anarchy: Neorealism to Structural Realism. N.Y.

Carr E. 1946. The Twenty Years' Crisis, 1919 - 1939: an Introduction to the Study of International Relations. L.

Czervinski T. 1998. Coping with the Bounds: Speculations on Nonlinearity in Military Affairs. Washington

Deudney D. 1995. The Philadelphian System: Sovereignty, Arms Control, and Balance of Power in the American States-Union, 1787 - 1861. - International Organization, № 49.

Deuney D. 1997. Geopolitics and Change. - Doyle M., Ikenberry J. (eds.) New Thinking in International Relations Theory. Boulder. 
Doyle M., Ikenberry J. (eds.) 1997. New Thinking in International Relations Theory. Boulder.

Fayerabend P. 1981. Philosophical Papers. Vol.1, 2. N.Y.

Gilpin R. 1981. War and Change in World Politics. N.Y., Cambridge.

Hirst P., Thompson G. 1996. Globalization in Question. Cambridge.

Hoffman S. 1965. The State of War. N.Y.

Ikenberry G., Lake D., Mastaduno M. (eds.) 1988. The State and American Foreign Economic Policy. Ithaca.

Jervis R. 1997. System Effects: Complexity in Political and Social Life. Princeton. Winter.

Kapstein E. 1991/1992. We Are U.S.: the Myth of Multinational. - The National Interest,

Kennedy P. 1987. The Rise and Fall of the Great Powers: Economic Change and Military Conflict from 1500 to 2000 . N.Y.

Keohane R., Nye J. 1977. Power and Interdependence. Boston.

Kissinger H. 1957. A World Restored: Gastlereage, Metternich, and the Problem of Peace, 1812 1822. Boston.

Krasner S. 1978. Defining the National Interest: Raw Materials Investments, and U.S. Foreign

Policy. Princeton.

Krasner S. 1985. Structural Conflict: the Third World against Global Liberalism. Berkeley.

Lake D. 1988. Power, Protection, and Free Trade. Ithaca.

Lane M. (ed.) 1970. Structuralism: a Reader. L.

Legro J, Moravchik A. 1999. Is Anybody Still a Realist? - International Security, vol.24, № 2

Mandelbaum M. 1988. The Fate of Nations: the Search for National Security in the 19th and 20th Centuries. Cambridge.

Mearsheimer J. 2001. The Tragedy of Great Power Politics. N.Y.

Miller D. 1994. Critical Rationalism. La Salle.

Modelski G. 1987. Long Cycles in World Politics. Seattle.

Morgenthau H. 1948. Politics among Nation. N.Y.

Piaget J. 1970. Structuralism. N.Y.

Popper K. 1959. The Logic of Scientific Discovery. N.Y.

Popper K. 1965. Conjectures and Refutations. N.Y.

Posen B. 1984. The Sources of Military Doctrine. Ithaca.

Ruggi J. 1983. Community and Transformation in World Polity: Toward a Neorealist Synthesis.

- World Politics, № 35.

Ruggi J. 1989. International Structure and International Transformation: Space, Time, and

Method. - Rosenau J., Czempiel E. (eds.) Global Changes and Theoretical Challenges. Lexington.

Russett B. (ed.) 1972. Peace, War and Numbers. Beverly Hills.

Snyder G. 1997. Alliance Politics. Ithaca.

Tellis A. 1996. Reconstructing Political Realism: the Long March to Scientific Theory. -

Frankel B. (ed.) Roots of Realism. Portland, L.

Walt S. 1987. The Origins of Alliances. Ithaca.

Waltz K. 1959. The Men, State and War. N.Y.

Waltz K. 1975. Theory of International Relations. - Greenstein F., Polsby N. (eds.)

International Politics. Handbook of Political Science. Vol.8. Reading.

Waltz K. 1979. Theory of International Politics. Reading.

Waltz K. 1989. The Origins of War in Neorealist Theory. - Rotberg R., Rabb T. (eds.) The

Origin and Prevention of Major Wars. Cambridge.

Waltz K. 1991. Realist Thought and Neorealist Theory. - Rothstein R. The Evolution of Theory in International Relations. Columbia.

Waltz K. 2000a. Globalization and American Power. - The National Interest, Spring.

Waltz K. 2000b. Structural Realism after the Cold War. - International Security, vol. 25, № 1.

Watkins J. 1984. Science and Skepticism. Princeton.

Wohlforth W. 1995. Realism and the End of the Cold War. - Brown M., Lynn-Jones S. (eds.)

The Perils of Anarchy: Contemporary Realism and International Security. Cambridge.

Wohlforth W. 1999. The Stability of a Unipolar World. - International Security, vol.24. № 1.

Wolfers A. 1962. Discord and Collaboration. Baltimore. 